found to be significantly increased only after 3 months of TNF-a blocking therapy compared to baseline. No significant changes during follow-up were found for collagen resorption marker SCTX Z-score. Collagen formation marker PINP $Z$-score was significantly increased after 3 and 6 months as well as 2 years of TNF-a blocking therapy. Bone mineralization marker BALP Z-score was significantly increased at all time points up to and including 2 years and returned to baseline levels during 4 to 8 years of TNF-a blocking therapy (Figure 1). Conclusion: In this subgroup of AS patients with established and active disease responding to TNF-a blocking therapy, we observed that the bone turnover balance favored bone formation during the first years of TNF-a blocking therapy, which corresponds to previously reported improvement in bone mineral density, especially at the lumbar spine. ${ }^{1}$ New finding of our study is that after 8 years of treatment, markers of bone resorption, formation, and mineralization were all comparable to baseline values.

References:

[1] Arends et al. Arthritis Res Ther. 2012;14(2):R98
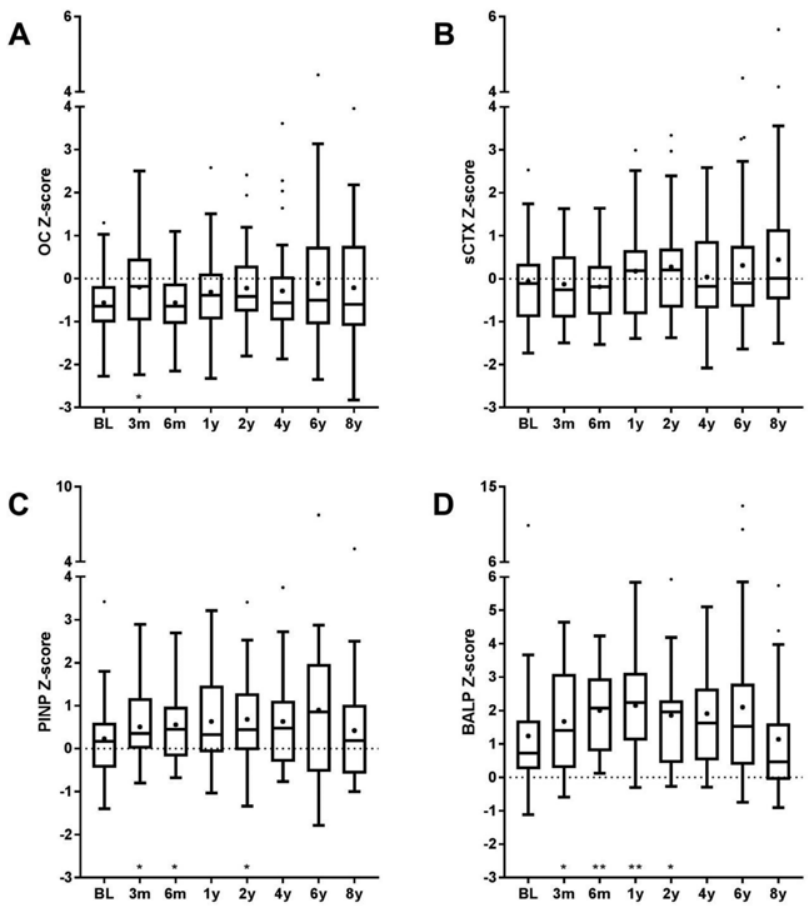

Figure 1. The effect of 8 years of TNF- $\alpha$ blocking therapy on bone formation markers OC (A), Figure 1. The effect of 8 years of TNF- $\alpha$ blocking therapy on bone formation markers $O C$ (A),
SCTX (B), PINP (C) and BALP (D) in patients with AS $(n=37)$. Z-scores were calculated to correc for the effect of age and gender on in patients with AS ( $n=37$ ). Z-scores were calculated to correct for the effect of age and gender on bone turnover. Box-and-whisker plots (Tukey). boxes indicate medians with interquartile ranges, $\bullet$ indicates mean; whiskers indicate 1.5 times interquar

Disclosure of Interests: : Mark Siderius: None declared, Anneke Spoorenberg: None declared, Suzanne Arends Grant/research support from: Grant/research support from Pfizer

DOI: 10.1136/annrheumdis-2020-eular.4461

\section{THU0403 \\ THE EFFECT OF SPINAL STABILIZATION EXERCISES ON SPINAL CURVES DIAGNOSED WITH ANKYLOSING SPONDYLITIS}

Y. Tunç ${ }^{1} .^{1}$ Hacettepe Üniversitesi Tıp Fakültesi, Ankara, Turkey

Background: Postural deformities can cause changes in spinal curvatures patients with ankylosing spondylitis. In these patients, preventive and therapeutic approaches are needed for spinal deformities (1). Positive effects of the spinal stabilization exercises are manifested in reducing pain, maintaining mobility, improving posture, increasing aerobic capacity and improving quality of life (2). Objectives: The aim of this study is to investigate the effect of stabilization exercises on spinal curvatures in s ankylosing spondylitis patients.

Methods: Twenty-eight ankylosing spondylitis patients (25 females, 3 males) with a mean age of $30.87 \pm 9.13$ years were included in the stabilization exercises program. The patients performed spinal stabilization exercises two days a week for six weeks. Stabilization training includes training of deep muscles providing diaphragmatic breathing, neutral spine position control training and local motor control, and motor control training of global muscles, dynamic stabilization exercises and strengthening training. Thoracic kyphosis and lumbar lordosis curvature of patients in an upright position were evaluated with Spinal Mouse (SM) device before and after therapy program. The SM device is a reliable, valid, safe, quick method that can be used in the clinics and researches of the adults with no side effects.

Results: At the end of 6 weeks of treatment, there was a decrease in the total curvature degree of the thoracic vertebrae in the sagittal axis $(\mathbf{p}=\mathbf{0 . 0 2 6})$. No significant difference was found in the lumbal region $(p=0.109)$.

Table 1. Differences of Total Curve Degrees

\begin{tabular}{lcccc}
\hline & $\begin{array}{c}\text { Pre-Exercises Program } \\
\text { Mean } \pm \text { SD }\end{array}$ & $\begin{array}{c}\text { Post-Exercises } \\
\text { Program } \\
\text { Mean } \pm \text { SD }\end{array}$ & z & p \\
\hline Thoracal Total Curve Degrees & $43.50 \pm 8.11$ & $42.57 \pm 7.70$ & -2.232 & $* 0.026$ \\
Lumbal Total Curve Degrees & $-26.42 \pm 8.46$ & $-23.77 \pm 7.15$ & -1.604 & 0.109 \\
\hline
\end{tabular}

${ }^{*} \mathrm{p}<0.05$, SD: Standart Deviation

Conclusion: Stabilization exercises are effective in reducing thoracic kyphosis in patients with ankylosing spondylitis patients. The use of these exercises in treatment programs will contribute significantly to improving spinal alignment and preventing postural deformities.

References:

[1] Grazio, S., Grubišić, F., \& Brnić, V. (2019). Rehabilitation of patients with spondyloarthritis: a narrative review. Medicinski Glasnik, 16(2).

[2] Gunay, S. M., Keser, I., \& Bicer, Z. T. (2018). The effects of balance and postural stability exercises on spa based rehabilitation programme in patients with ankylosing spondylitis. Journal of back and musculoskeletal rehabilitation, 31(2), 337-346.

Disclosure of Interests: : None declared

DOI: 10.1136/annrheumdis-2020-eular.6458

\section{THURSDAY, 04 JUNE 2020}

\section{Crystal diseases, metabolic bone diseases other than osteoporosis}

\section{THU0404 INFLUENCE OF URATE TRANSPORTOSOME FOR HYPERURICEMIA AND GOUT}

B. Stiburkova ${ }^{1,2}$, K. Pavelcova ${ }^{1,3}$, J. Bohata $^{3}$, M. Pavlikova $^{4}$, T. Takada $^{5}$, Y. Toyoda ${ }^{5}$, L. Hasikova ${ }^{3}$, J. Zavada ${ }^{1}$, K. Pavelka ${ }^{1} .{ }^{1}$ Institute of Rheumatology, Prague, Czech Republic; ${ }^{2}$ Charles University, Department of Pediatrics and Adolescent Medicine, First Faculty of Medicine, Prague, Czech Republic; ${ }^{3}$ Institute of Rheumatology, Department of Rheumatology, First Faculty of Medicine, Charles University, Prague, Czech Republic; ${ }^{4}$ Charles University, Department of Probability and Mathematical Statistics, Prague, Czech Republic; ${ }^{5}$ The University Tokyo Hospital, Department of Pharmacy, Tokyo, Japan

Background: Gouty arthritis, caused by a persistent increase in serum uric acid level, can be caused by underexcretion of uric acid by uric transporters; however, the effects of allelic variants of urate transportosome are yet to be fully determined.

Objectives: In this study we investigated the effects of 10 genes of urate transportosome in a cohort of patients with primary hyperuricemia and gout.

Methods: The cohort consisted of 114 hyperuricemic individuals; 207 gout patients; and 274 normouricemic controls.

Results: We identified 39 non-synonymous allelic variants in the 10 genes of urate transportosome in hyperuricemia/gout cohort. For 22 variants, a European MAF $<0.0001$ is documented. From the total of 39 identified variants we selected 23 variants for functional characterization based on a) finding of a newly identified variant, b) MAF variant was significantly different in the group of patients with hyperuricemia/gout, c) with high probability, in silico predictions showed devastating influence of variant on protein function.

Conclusion: Although further analyzes are needed to elucidate the contribution of urate transportosome to urate homeostasis, our results clearly show that $A B C G 2$ transporter analysis has significant clinical potential. Of the identified non-synonymous allelic variants of the urate transportosome, rs2231142 (p.Q141K) in the ABCG2 gene, proved to be the most clinically significant on the age onset $(P<0.0002$, Kruskal-Wallis test)

\section{References:}

[1] Toyoda Y, et al. Cells. 2019 Apr 18;8(4). 2. Stiburkova B, et al. Rheumatology (Oxford). 2016 Jan;55(1):191-4. 3. Toyoda Y, et al. Arthritis Res Ther. 2019 Oct 28;21(1):219

Acknowledgments: This study was supported by the grant from the Czech Republic Ministry of Health AZV 15-26693A and RVO 00023728. 
Disclosure of Interests: : Blanka Stiburkova: None declared, Katerina Pavelcova: None declared, Jana Bohata: None declared, Marketa Pavlikova: None declared, Tappei Takada: None declared, Yu Toyoda: None declared, Lenka Hasikova: None declared, Jakub Zavada Speakers bureau: Abbvie, UCB, Sanofi, Elli-Lilly, Novartis, Zentiva, Accord, Karel Pavelka Consultant of: Abbvie, MSD, BMS, Egis, Roche, UCB, Medac, Pfizer, Biogen, Speakers bureau: Abbvie, MSD, BMS, Egis, Roche, UCB, Medac, Pfizer, Biogen DOI: 10.1136/annrheumdis-2020-eular.5629

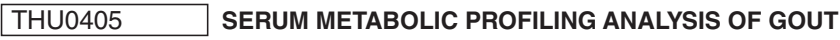 PATIENTS BASED ON UHPLC-Q-TOF/MS}

T. W. LI ${ }^{1}$, Y. Huang ${ }^{1}$, Z. Zhong ${ }^{1}$, Q. Huang ${ }^{1}{ }^{1}$ Guangdong Second Provincial General Hospital, Department of Rheumatology and Immunology, Guangzhou, China

Background: Gout is a common kind of inflammatory arthritis with metabolic dis orders. The detailed pathogenesis of gout remains largely unknown. Metabolomics has become an important tool in detecting the new pathogenesis and biomarkers. However, few studies have focused on the serum metabolic profiling of gout. Objectives: The study aims to investigate the metabolic profiling of gout patients with ultra-performance liquid chromatograph quadrupole time-of-flight mass spectrometry (UPLC-Q-TOF-MS), and explore the potential pathological mechanisms and biomarkers.

Methods: Serum samples from 31 gout patients and 31 healthy controls were analyzed by UPLC-Q-TOF-MS. Principal components analysis (PCA), orthog onal partial least squares-discriminant analysis (OPLS-DA) and Hierarchica clustering analysis were performed to detect different compounds between the two groups. Receiver operating characteristic (ROC) curve analysis and pathway analysis of the different metabolites were conducted.

Results: A total of 9192 compounds were detected, of which 138 significantly different compounds were selected, according to the criteria of (Variable importance in projection $(\mathrm{VIP})>3, P<0.05)$. Eventually, 96 reliable metabolites matched the HMDB database were confirmed. ROC curve results showed that the area under the curve (AUC) value of 4-hydroxytriazolam for gout was 0.933 (C195\%: 0.875-0.992), yielding a highest AUC value, with the sensitivity of $83.9 \%$ and specificity of $93.5 \%$. The pathway analysis results indicated that the significantly different metabolites were mainly involved in "primary bile acid biosynthesis", "purine metabolism" and "glycerophospholipid metabolism".

Conclusion: The serum metabolic profiling in gout patients were significantly different from healthy subjects. 4-hydroxytriazolam was the potential biomarkers. Primary bile acid biosynthesis may be a novel metabolic pathway of gout.

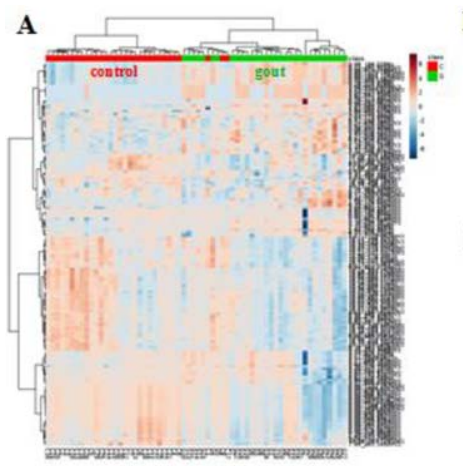

B

Figure.1 A: Hierarchical clustering analysis of the significantly different compounds B: Pathway analysis of the significantly different metabolites.

References:

[1] Banoei MM, et al. Metabolomics and Biomarker Discovery in Traumatic Brain Injury. J Neurotrauma, 2018. 35(16): p. 1831-1848.

Disclosure of Interests: : None declared

DOI: 10.1136/annrheumdis-2020-eular.5963

\section{\begin{tabular}{|l|l}
\hline THU0406 IDENTIFICATION OF INTRACELLULAR VACUOLES IN \\
\hline
\end{tabular} SYNOVIAL FLUID WITH CALCIUM PYROPHOSPHATE AND MONOSODIUM URATE CRYSTALS}

M. L. Peral ${ }^{1}$, I. Calabuig ${ }^{1}$, A. Martín-Carratalá ${ }^{1}$, M. Andrés ${ }^{1}$, E. Pascual ${ }^{1}$. ${ }^{1}$ Hospital General Universitario de Alicante, Reumatología, Alicante, Spain

Background: Synovial fluid analysis using polarized microscopy is the gold standard for the diagnosis of crystal-related arthritis. In our experience, we have noted that, when calcium pyrophosphate (CPP) crystals are observed, they sometimes appear within intracellular vacuoles. However, this phenomenon is not seen in those samples containing monosodium urate (MSU) crystals. This finding has been scantly reported in the literature, but may be useful in clinical practice to ensure accurate crystal identification.

Objectives: Our study aims to assess whether the presence of vacuoles contributes to identifying the type of crystal, and also to gauge the frequency of their presentation.

Methods: We conducted an observational study in a rheumatology unit between February and June of 2019. Synovial fluids containing CPP or MSU crystals obtained in daily clinical practice, were consecutively included for analysis. Two observers simultaneously analyzed the presence of vacuoles by ordinary ligh and phase contrast microscopy in less than 24 hours after their extraction, using a microscope equipped with two viewing stations. The primary study variable was to determine whether CPP and MSU crystals are seen inside intracellular vacuoles, and to calculate the frequency of this finding for each type of crystal estimating their $95 \%$ confidence interval $(95 \% \mathrm{Cl})$ and comparing rates using Fisher's exact test.

Results: Twenty-one samples were obtained. Data is given in the Table. MSU crystals were present in 7 (33.3\%) and CPP crystals in $14(66.6 \%)$. Interestingly, none of the MSU samples showed crystal-containing vacuoles (95\% C $0-35.4 \%)$. On the contrary, cytoplasmic vacuoles containing crystals were present in all of the CPP samples (95\% Cl 78.5-100\%). The findings were confirmed by phase-contrast microscopy. Differences were statistically significant $(p<0.001)$.

Table.

SAMPLES ACCORDING SAMPLES WITH VACUOLS SAMPLES WITH VACUOLS

TO TYPE OF (UNDER ORDINARY LIGHT) (UNDER PHASE CONTRAST)

MICROCRYSTAL $(n=21)$

CPP $(14 ; 66.6 \%) \quad 14(100 \%)(95 \% \mathrm{Cl} 78.5-100 \%) 14(100 \%)(95 \% \mathrm{Cl} 78.5-100 \%)$

MSU $(7 ; 33.3 \%)$

$0(0 \%)(95 \% \mathrm{Cl} 0-35.4 \%) \quad 0(0 \%)(95 \% \mathrm{Cl} 0-35.4 \%)$

Conclusion: The presence of vacuoles may be a useful and easy way to differentiate MSU and CPP crystals when performing synovial fluid microscopy in clinical practice, since it appears to be a distinctive feature in CPP crystal fluids. References:

[1] Kohn NN, Hughes RE, McCarty DJ Jr, Faires JS. The significance of calcium phosphate crystals in the synovial fluid of arthritic patients: the «pseudogout syndrome». II. Identification of crystals. Ann InternMed. 1962 May;56:738-45.

[2] Pascual E, Sivera F, Andrés M. Synovial Fluid Analysis for Crystals. CurrOpRheumatol 2011;23:161-169.

[3] McCarty DJ, Koopman WJ. Arthritis and allied conditions: A textbook of rheumatology, volumen 1. Lea \&amp;Febiger. 1993.

[4] Pascual E, Sivera F. Synovial fluid crystal Analysis. En Gout and other crystal arthropathies. Terkeltaub R ed. Elsevier; 2012: p.20-34.

[5] Hwang HS, Yang CM, Park SJ, Kim HA. Monosodium Urate Crystal-Induced Chondrocyte Death via Autophagic Process. Int J Mol Sci. 2015 Dec 8;16(12):29265-77.

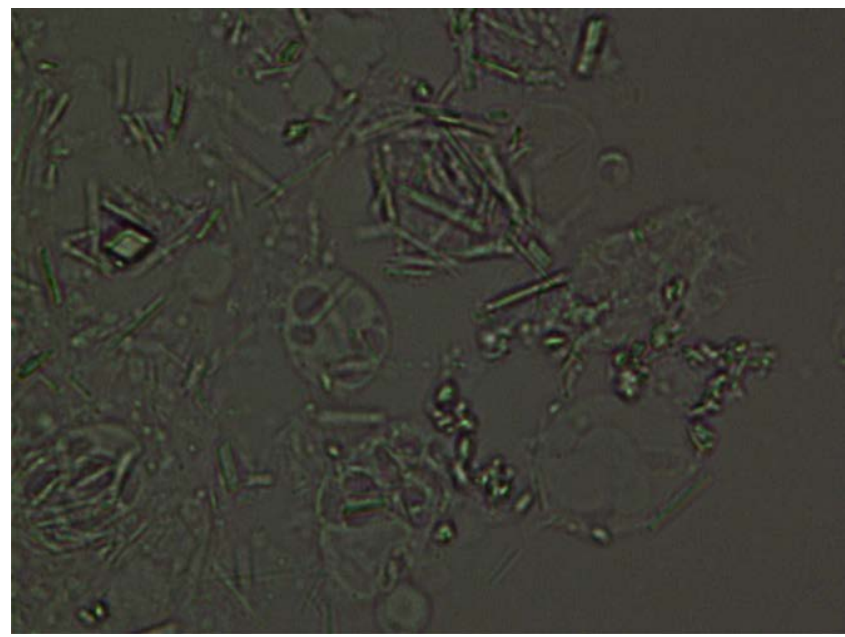

Image 1. Microscopy with ordinary light. Cells with cytoplasmic vacuoles are observed, as well as abundant intra and extracellular CPP crystals. 